\title{
A EDUCAÇÃO PARA A SAÚDE DOS TRABALHADORES NO CONTEXTO DA ACUMULAÇÃO FLEXÍVEL: NOVOS DESAFIOS
}

\author{
EDUCATING WORKERS FOR HEALTH IN A FLEXIBLE \\ ACCUMULATION CONTEXT: NEW CHALLENGES
}

Elizabeth Garzuze da Silva Araújo 1

Resumo Este artigo apresenta parte dos resultados de uma pesquisa com trabalhadores numa refinaria de petróleo, durante a implantação de novas tecnologias em sua planta industrial. A pesquisa buscou verificar o que estas modificações no processo de trabalho produzem na saúde dos trabalhadores. Os resultados mostraram que as novas tecnologias de automação alteram o conteúdo do trabalho, pois a máquina embute a ciência, não deixando mais transparecer o nexo causal entre a doença e a ferramenta de trabalho. Com base nos resultados, discutem-se aspectos que podem contribuir para a construção de uma nova pedagogia de educação para a saúde, que tome o trabalho como princípio educativo.

Palavras-chave novas tecnologias; trabalho como princípio educativo; educação para a saúde; saúde do trabalhador.
Abstract This article presents the partial results of a research carried out with the workers of an oil refinery during the implantation of new technologies in their industrial plant. The research attempted to identify what effects these changes in the work process had on the workers' health. The results showed that the new automation technologies altered the work content, in the sense that science becomes imbedded in the machine and the causal nexus between the illness and the work tool is no longer apparent. On the bases of the results, we discuss aspects that may contribute to the construction of a new pedagogy of education for health that uses work as its educational principle.

Key words new technologies; work as an educational principle; education for health; workers' health. 
"A doutrina materialista da transformação das circunstâncias e da educação esquece que as circunstâncias têm de ser transformadas pelos homens e que o próprio educador tem que ser educado".

Karl Marx

"O que é a globalização? Não vamos escravizar só os nossos. Vamos escravizar o resto do mundo. Noventa e nove por cento dos trabalhadores já foram escravizados na sua consciência".

Operador de Processo da Petrobras

\section{Introdução}

O novo regime de acumulação capitalista fundado na reestruturação produtiva e nas inovações tecnológicas, denominado por Harvey "acumulação flexível", tem produzindo inúmeras modificações no mundo do trabalho. A busca de estratégias para o aumento do lucro baseadas "na combinação da mais-valia absoluta e da mais valia relativa" (Harvey, 1996, p.174, grifos nossos) $)^{2}$ traz para a classe dos trabalhadores alterações profundas no modo de produção da sua existência.

Para responder à globalização da economia com suas exigências de maior competitividade e qualidade, esse novo processo de acumulação introduz modificações na base técnica do trabalho, com a implantação de novas tecnologias baseadas na microeletrônica, na telemática e na informática. Também as velhas formas de gestão e de organização da produção de base taylorista-fordista vão sendo substituídas por novos processos baseados na flexibilização "dos mercados de trabalho, dos produtos e padrões de consumo" (Harvey, 1996, p. 140).

Essas modificações vêm como resposta a uma crise do capital inaugurada a partir da década de 1970, com a diminuição do ritmo de crescimento econômico e o aumento da inflação nos países industrializados. Uma crise que, segundo Braga,

“é o produto mais evidente da síntese das contradições e antagonismos amadurecidos no âmbito de uma particular correlação de forças estabelecida entre a burguesia, classes subalternas e Estados-nações ao longo do processo de expansão do imperialismo ocidental em concorrência com o bloco coletivista de Estado (o chamado "socialismo realmente existente"), entre os anos 50 e 70 desse século" (Braga, 1997, p. 155).

Uma crise econômica e política que: 


\begin{abstract}
“apresenta-se sob a forma de uma dupla existência: crise generalizada das exigências da acumulação do capital em nível internacional, articulada à crise dos fundamentos do consentimento das classes subalternas ao projeto colonialista ou neocolonialista, no âmbito da formação nacional específica, incluindo aí a crise generalizada da estratégia welfare do Estado burguês para o caso dos países imperialistas. Tal crise demandaria, por assim dizer, um processo permanente de coordenação da complexa relação existente entre as forças produtivas, as estruturas multinacionais de poder e os aparelhos hegemônicos de Estado" (Braga, 1997, p. 157).
\end{abstract}

Para Harvey (1996), as décadas de 1970 e 1980 caracterizaram-se por grandes mudanças no mundo do trabalho, com o esgotamento do sistema fordista-keynesiano de acumulação intensiva, da produção em massa e a sua substituição, em alguns lugares, pelo regime da acumulação flexível, trazendo mudanças profundas principalmente para a classe que vive do trabalho, ou seja, os trabalhadores. Inaugura-se, assim, uma nova etapa de acumulação, com características inteiramente novas baseadas na flexibilidade, emoldurando uma nova cultura.

A acumulação flexível articula um alto desenvolvimento tecnológico com uma desconcentração produtiva com base em pequenas e médias empresas. Estão, portanto, em curso modificações em todo processo produtivo, ou seja, em sua base técnica e na organização do trabalho, a fim de aumentar a produtividade, reduzindo os custos da produção. São modificações da organização industrial e da vida social e política, caracterizando uma etapa que pode ser reconhecida como um regime de acumulação inteiramente novo, associado a um sistema de regulamentação política e social bem distinta. (Braga, 1997).

Além da implantação das novas tecnologias, instala-se uma nova ordem política com a perda da capacidade de influência dos Estados-nação na acumulação do capital e na sustentação de suas políticas compensatórias.

\footnotetext{
“Na nova etapa de globalização o Estado-nação perdeu a capacidade de influenciar a acumulação de capital invertendo a relação de poder: ao invés do governo nacional coordenar e induzir os grandes blocos de inversão de capital, é o capital global que dita ao governo nacional as condições para que ele venha a se inverter no país" (Singer, 1996, p. 6).
}

As proposições neoliberais passam a ser a nova racionalização teórica, quebrando o domínio político exercido pelo movimento operário que tinha se fortalecido na conquista de direitos. Nessa forma de regulação, os trabalhadores são incorporados ao processo de restruturação mediante um sistema de trocas compensatórias, pelo qual se consegue seu compromisso com a produtividade e a qualidade. Todos os incentivos para os trabalhadores 
são reais, porém o seu envolvimento é direto com a gerência e não depende de um acordo coletivo. São formas de enfraquecimento da resistência das classes trabalhadoras, que puderam ser verificadas nesta pesquisa, e estão representadas na fala de um dos trabalhadores:

“Eu acho que não existe mais sindicato no Brasil, porque se o nosso, que todo mundo fala que é o mais forte, não consegue fazer nada... Ninguém quer fazer greve, ninguém quer fazer paralisação, não adianta fazer assembléia. Como se dissesse: este pacote foi imposto, é esse e não adianta... O que aconteceu é que com aquelas multas absurdas que o governo impôs ao sindicato, mais as demissões dos colegas por causa da greve, o pessoal esmoreceu... tudo que está sendo feito é para privatizar..." (Operador de Processo - OP).

Todas essas formas sutis de disciplinamento para o aumento da produtividade podem trazer conseqüências sérias e imediatas à saúde do trabalhador, pois a necessidade crescente de produzir mais e com maior qualidade, a fim de aumentar o salário, gera uma intensificação do ritmo de trabalho. De acordo com os operadores esse ritmo intenso já é evidente:

"Quando entrei aqui a gente trabalhava com seis operadores na área, operava tranqüilo, com uma folga enorme, você fazia o que te cabia e pronto. Agora com quatro, não, você acaba ficando responsável por mais coisas, são quatro pessoas para aquela mesma quantidade de trabalho e com número reduzido" (OP).

“Hoje o pessoal sai daqui esgotado. O cara sai andando porque não dá pra sair de quatro. Sai do trabalho esgotado, principalmente no horário de $8 \mathrm{~h}$ às $16 \mathrm{~h}$. Veja bem, as incoerências, a unidade está ficando velha, está aumentando a necessidade de manutenção, diminui a qualidade da manutenção, diminui o número de operadores, isto aí sobrecarrega os que ficaram, é claro, evidente. Não sei como não conseguem enxergar isto. A gente sai daqui parece que jogou umas quatro partidas de futebol seguidas. A gente sai desgastado" (OP).

A situação é mais grave nas economias do Terceiro Mundo, que passaram ao domínio de um novo imperialismo, um sistema de dominação internacional com base no capital especulativo das grandes instituições financeiras e das corporações transnacionais, sem terem tido tradição na produção industrial (Singer, 1996; Braga, 1997).

As classes dominantes nestes países elegeram como eixo central de suas políticas o pagamento da dívida externa e o ajuste estrutural. Assim, sob a égide do Banco Mundial, do Fundo Monetário Internacional (FMI), da Organização Mundial do Comércio (OMC) e da Organização das Nações Unidas (ONU), os países do Terceiro Mundo adotam políticas de redução orçamen- 
tária nas suas políticas sociais — principalmente da educação e da saúde bem como a privatização de empresas públicas e produção para exportação em prejuízo de seus mercados internos. Trata-se de uma política de ideologia neoliberal composta com a seguinte base: a abertura comercial, as privatizações, a desregulamentação financeira, o que contribui para a dissolução do Estado e do capital nacional (Braga, 1997).

No Brasil, este projeto teve início no governo Sarney, muito embora tenha sido o governo Collor quem adotou a nova concepção, quando colocou em sua agenda o desmonte do Estado e o programa de privatização como precondições para o combate à inflação. Os autores Teixeira (1998) e Fernandes (1995) se referiram ao projeto:

"Além disso, é no seu governo que é lançado o programa de reestruturação produtiva, segundo o qual as empresas deveriam procurar um processo de gestão pela qualidade e produtividade, único caminho capaz de torná-las mais competitivas para entrarem no chamado mundo desenvolvido, com colaboradores mais felizes e engajados, numa relação em que todos - patrões, empregados e a sociedade sejam vencedores (...). O Primeiro Mundo exige qualidade como premissa; ser certificado pelo ISO é, sem dúvida, o melhor para nele ingressar" (Teixeira, 1998, p. 25 , grifos nossos).

“Essa maré privatizante marca uma ruptura muito clara com as estratégias industriais anteriores, que valorizavam as empresas públicas como instrumentos fundamentais para um desenvolvimento econômico soberano. Esse processo se faz sentir com muita força hoje no Brasil — não só com as privatizações já efetuadas nos últimos quatro anos, mas também com as proposições de quebra de monopólios estatais considerados 'intocáveis' até aqui, como o petróleo e as telecomunicações... A adoção desse projeto implica no desmonte de instrumentos fundamentais de defesa da soberania nacional..." (Fernandes, 1995, p. 56-57, grifos nossos).

Essas mudanças podem alterar a saúde dos trabalhadores, trazendo conseqüências diversas para sua vida e, também, gerar novas patologias. Por isso, trazem grandes desafios aos estudiosos da saúde no trabalho, uma vez que a expressão dos seus efeitos tem sido traduzida muito mais pelo aumento das alterações psíquicas e psicossomáticas, do que pelas manifestações tradicionalmente avaliadas no campo da Saúde Ocupacional, como aquelas decorrentes do comportamento e estilo de vida, de riscos e de acidentes numa relação causa-efeito, típicas do taylorismo-fordismo (Dejours, 1999). Tal quadro exige novos estudos nesse campo do conhecimento, de modo a contribuir para uma modificação dos processos educativos de promoção e proteção à saúde, hoje centrados na responsabilidade individual e na prevenção de riscos. 
Por ser esse um momento de alterações significativas no trabalho, torna-se privilegiado para a reflexão e compreensão sobre como se dá a exploração capitalista frente ao atual processo de acumulação, que impõe tantas perdas aos trabalhadores, embora se apresente com o discurso da autonomia, da flexibilidade e da qualidade. Tais reflexões devem abarcar as novas perdas do trabalho com suas conseqüências sobre a saúde dos trabalhadores, que se tornam mais agravadas em países onde o Estado do Bem-Estar Social sequer foi plenamente alcançado, como nos países da América Latina.

Tendo como eixo o fundamento da teoria marxista - o homem produzindo por meio do trabalho as condições de sua existência e de sua consciência - , procurou-se identificar nesta pesquisa as alterações sobre a saúde dos trabalhadores (operadores) do Setor de Craqueamento Catalítico (SECRA) - local de refino do resíduo nobre do petróleo - de uma refinaria da Petrobras, após a introdução de novas tecnologias, a fim de indicar pontos para a discussão de novas formas de educação para a sua saúde no trabalho.

Tomou-se a categoria trabalho como central na análise, pela necessidade de esclarecer que mediações operam atualmente entre as condições reais de produção e de reprodução dos trabalhadores do petróleo e suas relações com o processo saúde-doença no trabalho. Foi realizado um estudo de caso, composto por observações diretas e entrevistas nos três turnos de trabalho com doze petroleiros do SECRA, que tinham tido dois ou mais afastamentos por doença durante a implantação do novo instrumental de trabalho o Sistema Descentralizado de Controle Digital (SDCD)3. Buscou-se, também, compreender sua concepção sobre o processo saúde-doença no trabalho, para avaliar seu conhecimento acerca destas novas mudanças e das alterações sobre a sua saúde.

\section{A acumulação flexível e a saúde dos petroleiros no trabalho}

“O ser humano tem uma capacidade de adaptação fantástica, mas dentro de um limite, tanto que o limite tá na quantidade de risco que você tá tendo. Você vê que tá aumentando casos de hipertensão, problemas cardíacos, isto é um ônus que a sociedade tá pagando, estamos entrando naquele limite do ser humano. Tudo bem, o interessante é produzir, mas estamos chegando naquele ponto que o ser humano já não agüenta mais isto. Eu acho a tecnologia fantástica, ela só vem para melhorar, e nessa evolução tecnológica que estamos tendo, nos próximos cinco anos, vamos evoluir logicamente mais do que os últimos trinta anos. O problema é o uso que se vai fazer dela" (OP).

Na área energética, segundo Salgado e Pertence Neto (1993, p. 11), “as duas crises do petróleo, em 1973 e 1979, elevaram os preços causando pânico nos governos dos países consumidores". Este fato levou os segmentos da 
economia a buscarem formas de economizar energia a partir de mudanças tecnológicas e organizacionais. Como na indústria petrolífera, a produtividade resulta diretamente do rendimento global das instalações e da performance dos equipamentos, muito mais do que do ritmo de trabalho. $\mathrm{O}$ advento dos computadores permitiu a utilização de tecnologia física de base microeletrônica cada vez mais intensa na indústria nacional que implementou seu uso nas refinarias (Castro e Guimarães, 1991).

No esforço constante de reduzir a dependência do petróleo importado, a Petrobras investiu fortemente no desenvolvimento de tecnologias, equipamentos e recursos humanos, e passou a ser reconhecida internacionalmente nas suas diversas áreas de atuação, principalmente em pesquisa tecnológica. Dominou a tecnologia dos Sistemas Digitais de Controle Descentralizado (ou Distribuído), que, implantados em fins de 1988 em algumas das refinarias, possibilitaram o desenvolvimento e aperfeiçoamento de programas para otimização global da produção, a partir da integração dos Centros Integrados de Controle (CIC) (Duarte, 1995).

A concepção dos CIC em refinarias de petróleo tornou-se, desde a década de 1980, uma tendência mundial em busca do aumento da produtividade. Com esta integração, a disposição do controle do processo de refino passa a se dar em ilhas de operação num computador, o que permite o controle de diversas malhas ao mesmo tempo, substituindo os enormes painéis de parede que controlavam cada sistema separadamente. Isto requer modificações ambientais diversas, como a melhora da climatização do local para maior proteção dos equipamentos; modificação na iluminação, por causa das telas dos computadores, na postura de trabalho dos operadores, no conteúdo do trabalho; além de implicar menor circulação de pessoas (Duarte, 1995 op.cit).

Portanto, a integração do processo de trabalho somada à implantação da tecnologia física baseada em SDCD forma a base das mudanças tecnológicas recentemente implantadas nas indústrias petroquímicas. "Neste projeto, as equipes de trabalho passam a ser responsáveis pelo controle de diferentes unidades de produção, o que, de acordo com as experiências internacionais, possibilitaria a redução do número de operadores" (Duarte, 1994, p. 1).

Com isso, as empresas contam com uma medida eficiente na redução dos custos, diminuindo não só a mão-de-obra, mas também a intervenção no processo alcançado por uma maior estabilidade.

As modificações situam-se principalmente no âmbito da melhoria do controle do processo, o 'ponto nevrálgico' da transformação petroquímica, visando igualar a produção à capacidade efetiva das máquinas, minimizando, assim, o número de horas paradas para manutenção. Numa conjuntura de crise econômica e diante da necessidade de aumentar a produtividade, este aprimoramento trouxe "como desafio o domínio de uma tecnologia autóctone, uma vez que a indústria petroquímica foi construída ba- 
seada na aquisição de pacotes desenvolvidos no exterior" (Castro e Guimarães, 1991, p. 46).

Em 1989, o Plano Diretor de Automação Industrial (PDAI) da Petrobras foi reorientado com o traçar de novas diretrizes, que enfatizavam uma abordagem sistêmica e estruturada da área de automação industrial, buscando uma otimização do processo produtivo, naquele momento, o principal objetivo do plano. Também propôs como metas: a otimização do processo (operação), a otimização da produção, automatização de procedimentos e integração operacional (confiabilidade, segurança e recursos humanos); apoio (manutenção e engenharia) e gerência" (Petrobras, 1989).

No planejamento estratégico para o período 1992/2001, a automação passou a constituir um projeto auxiliar, Projeto Estratégico de Automação, visando à utilização desta tecnologia no seu grau máximo em termos de produtividade e competitividade. Do ponto de vista da empresa, a automação industrial tem também como objetivos, além da redução de custos, um controle mais efetivo dos parâmetros de produção e o afastamento do trabalhador de determinados ambientes de riscos (Revista da Petrobras, 1996).

A rentabilidade maior da indústria petroquímica hoje está justamente na transformação dos resíduos e depende fundamentalmente de um processo estável. Esta estabilidade é garantida pela qualidade dos equipamentos e pela atuação imediata do trabalhador na correção dos desvios que possam acontecer no processo. Para os operadores entrevistados, a indústria petrolífera é a que possui os maiores lucros, conforme registrado na seguinte fala:

\footnotetext{
“Na área de refino do petróleo, as maiores empresas no mundo passaram a introduzir sistemas de automação industrial, de base microeletrônica, permitida pelos avanços na área da informática. As três coisas que mais dão lucro no mundo são: uma refinaria bem administrada, uma refinaria média administrada e uma refinaria mal administrada" (OP).
}

A partir do PDAI/89, cada refinaria gerou um Plano de mudanças em seus processos de produção. Na estudada, foi possível verificar que entre os princípios descritos em seu Plano há muitos pontos pela busca de maior produtividade, que coincidem com aqueles descritos pelos estudiosos da atual etapa de acumulação do capital. Baseado na 'flexibilização', as mudanças nele introduzidas estão voltadas fundamentalmente para a redução da força de trabalho, propiciada, no caso das indústrias petroquímicas, por: integração das salas de controle, introdução da polivalência com vistas a multifunção, flexibilização da organização do trabalho, terceirização dos serviços e redução de direitos já conquistados.

A Refinaria estudada iniciou seu processo de inclusão de novas tecnologias em 1995, com a integração física das salas de Controle de Processos, 
para implantação do SDCD no SECRA. Procedeu-se, então, à alteração na gestão e na organização do trabalho, com modificações na composição das equipes, no treinamento dos operadores, no conteúdo do trabalho, na supervisão, no espaço físico, na posição de trabalho, na segurança e nas formas de controle.

As alterações no processo de trabalho e de gestão, já implantadas ou em implantação, parecem apontar para as diretrizes do processo de adequação da Petrobras ao atual processo de reestruturação produtiva em curso no país.

Na indústria petrolífera nacional,

“Os desenvolvimentos futuros serão: o controle avançado e otimização do processo, a racionalização do uso da força de trabalho (redução de postos com as aposentadorias), reorganização do trabalho, (visando adequar a sua estruturação de modo a aumentar a produtividade), a implantação de simuladores de processo para treinamento dos operadores (visando o aumento da qualificação média do pessoal), a automatização de procedimentos (como tarefas repetitivas, abertura e fechamento de válvulas, objetivando paradas de emergência em condições seguras e a diminuição da exposição do elemento humano a condições inseguras ou insalubre), e a implantação e utilização cada vez maior de analisadores em linha" (Duarte, 1995, p. 5, grifos nossos).

Estas modificações geram para os trabalhadores envolvidos uma grande insegurança, pois são atingidos setores vitais do processo de trabalho, dentre os quais a manutenção, a área dos treinamentos, a qualidade da terceirização, a perda do saber tácito com as aposentadorias, a perda de direitos.

Pesquisa anterior indicou que a redução dos postos de trabalho nas refinarias aconteceu

"principalmente nas áreas de manutenção e operação, além de uma forte queda no setor administrativo, o que aponta para uma aceleração da terceirização ou subcontratação da mão de obra principalmente para a manutenção. Apesar de não ter ocorrido o mesmo com o quadro de técnicos de nível superior, o quadro atual é o menor de toda história da refinaria, acarretando uma perda significativa da qualificação das equipes de operação e uma dificuldade de reposição" (Duarte, 1995, p. 23).

A saída dos trabalhadores mais experientes tem um significado muito especial para a indústria de petróleo. Trata-se de uma área industrial extremamente perigosa e com uma especificidade de trabalho bastante complexa. Ou seja, se houver necessidade de operadores numa refinaria, não se pode simplesmente procurá-los no mercado, porque não há trabalhadores disponíveis com o preparo requerido. Desta forma, a redução de postos de tra- 
balho traz para os petroleiros um agravamento do nível de insegurança pelo fato de se aumentar o risco implicado na integridade da planta industrial e também da extensa área que a envolve no caso de uma explosão.

Para os operadores a antecipação da redução do número dos trabalhadores na refinaria evidenciou-se da seguinte forma:

“Esta política de redução de número foi mais em função da implantação da qualidade total, da certificação de produtos da empresa, então houve um atropelo. $\mathrm{O}$ SDCD simplesmente foi uma ferramenta nesta mudança, no trabalho ele não facilitou, o que facilitaria seria a automação industrial, que é uma outra etapa. Nesta etapa é que viria a redução do pessoal. Então houve um atropelo. Eles implantaram o SDCD e foram cortando pessoal, achando que o SDCD diminuiu o trabalho do pessoal da área, e não aconteceu isso" (Operador Industrial Especializado - OIE).

Os operadores se referiram ao aumento da insegurança, com a perda da experiência dos trabalhadores mais antigos que dominavam todo processo de trabalho, representada na fala a seguir:

“A gente perdeu é o fator experiência. Teve um monte de gente experiente que saiu. Hoje o pessoal experiente sou eu, que sou relativamente novo para os padrões da época. Mesmo porque tem coisas que eu ainda não sei porque não peguei esta unidade desde o começo, apesar de dez anos de refinaria" (OIE).

"Sem dúvida nenhuma a gente aprende muito com os outros operadores. A teoria te ajuda, mas como tudo na vida: na prática a teoria é diferente. Então é com os colegas mais experientes que a gente aprende mais" (OP).

A redução do pessoal próprio na manutenção e a precariedade das terceirizadas e subcontratadas geram intranqüilidade com a segurança provocando grande ansiedade, assim manifestada:

“O que entendem aqui dentro por terceirização é ficar livre de problemas e de empregados problema. Isso mexe com a segurança das pessoas, tira totalmente a motivação porque a questão do salário já é fato relevante" (OP).

“a gente perdeu em mão-de-obra, a unidade está mais velha, o SDCD é um sistema novo, os equipamentos da área estão mais desgastados, está furando tubo aí, enfim a unidade esta ficando bem mais perigosa" (OIE).

A insegurança também esta presente quando precisam operar simultaneamente mais de uma máquina, caracterizando-se como polivalentes, conforme o depoimento a seguir: 
"Acho que a melhoria da tecnologia acaba implicando em multifunção, porque a gente vai fazer mais coisas ou ser responsável por mais coisas, porque o sistema vai fazer coisas que a gente fazia antes, a gente vai deixar de cuidar de coisas pequenas, porque os sistema cuida automaticamente. Isso em situação normal, eu tenho medo na emergência" (OP).

A diminuição do número de operadores modificando a composição dos grupos provoca uma quebra da homogeneidade das equipes de trabalho, tanto em termos do conhecimento, quanto em companheirismo, afinidade. Esta afinidade, segundo os operadores, é fundamental para o desenvolvimento do trabalho. Auxilia em momentos de dúvidas produzindo a segurança necessária que é fundamental nas emergências. Isso foi mencionado na seguinte fala:

“a diminuição do número de pessoas nos grupos vai influeciar todo grupo, o relacionamento, a união do grupo, o companheirismo, vai influenciar muito mais que a automação" (OP) .

Com isso, pode-se inferir que estão sendo criados novos e diferentes momentos de tensão e desgaste, em que o significado do corpo doente parece tomar hoje uma dimensão mais profunda, uma vez que as determinações dos agravos não são mais transparentes e exigem ações que vão além da prevenção e da higiene para defesa do corpo.

Como medir, por exemplo, o sofrimento dos trabalhadores do petróleo com a privatização da empresa e a conseqüente flexibilização dos direitos trabalhistas, e qual o significado desse ato na determinação da sua saúde? Uma empresa que ajudaram a construir e que durante a década de 1980 foi uma das indústrias petrolíferas que mais cresceu no mundo, justamente por ser uma estatal e por deter o monopólio. Para esses trabalhadores, a privatização tem um significado muito mais profundo porque rompe com um símbolo de nação. Rompe com uma concepção não só de domínio tecnológico, mas fundamentalmente com uma concepção de nacionalidade, de soberania nacional, que foi associada à construção do Estado de Bem-Estar. A privatização torna-se assim, um sofrimento político, ou como Dejours (1999), o denominou, um sofrimento ético.

$\mathrm{O}$ que as atuais modificações no trabalho da refinaria têm demonstrado é que se exige do trabalhador individual e coletivo uma superação de si mesmo para que possa vencer todos os concorrentes, em qualquer campo, tornando a sobrevivência uma guerra sem fronteiras, conforme verificado no seguinte depoimento:

“Hoje o pessoal sai daqui esgotado. O cara sai andando porque não dá pra sair de quatro. Sai do trabalho esgotado, principalmente no horário de $8 \mathrm{~h}$ às $16 \mathrm{~h}$. Veja 
bem, as incoerências, a unidade está ficando velha, está aumentando a necessidade de manutenção, diminui a qualidade da manutenção, diminui o número de operadores, isto aí sobrecarrega os que ficaram, é claro evidente, não sei como não conseguem enxergar isto. A gente sai daqui parece que jogou umas quatro partidas de futebol seguidas. A gente sai desgastado" (OP).

É uma guerra econômica, em que, segundo Dejours (1999, p. 13), “o fundamental não é o equipamento militar ou o manejo de armas, mas o desenvolvimento da competitividade"; uma guerra com "beneficiários, que desfrutam de uma prosperidade e de uma riqueza que os demais admiram e invejam", e em que "estão em jogo a sobrevivência da nação e a garantia da liberdade" (Dejours, 1999, p. 15, grifos do autor).

Para isso, é necessário destruir princípios, valores e conceitos, e modificar hábitos e costumes. Do trabalhador, exige-se que tenha autonomia para realização das tarefas, que analise, interprete e, se necessário, corrija instruções. Portanto, um trabalhador que pense, que tenha iniciativas próprias, que seja capaz de mudar rapidamente de uma atividade a outra: um trabalhador que seja capaz de produzir, vender, consertar os defeitos da máquina, limpar o chão, dar e receber ordens, ser multifuncional, polivalente, um trabalhador com um elevado grau de responsabilidade e uma alta qualificação para que possa dar conta das máquinas inteligentes e de uma organização de trabalho flexível. Exige-se um trabalhador que coopere, que seja organizado, equilibrado, disciplinado, que tenha poder de concentração e que seja assíduo:

“Em síntese, as empresas querem um trabalhador particular que incorpore as forças do trabalhador coletivo, antes divididas entre diversos trabalhadores singulares. Não querem mais um trabalhador coletivo combinado, mas um trabalhador que seja a síntese da combinação de diversas operações parciais" (Teixeira, 1998, p. 215).

Quando se avalia o uso ampliado da tecnologia baseada em máquinas inteligentes, observa-se que, ao invés de diminuir o sofrimento no trabalho, por substituir os trabalhadores em tarefas danosas à sua saúde, eliminando a exigência do esforço físico, elas têm provocado um aumento de tarefas com elevada carga cognitiva que envolve uma maior vigilância e controle do processo. Isso tem trazido sofrimentos ainda pouco descritos pela ciência e pouco debatidos pelas organizações dos próprios trabalhadores. Alguns estudos nesta área têm sido feitos mediante observações e "levantamentos que incluem aspectos subjetivos da percepção e cognição do próprio trabalhador" (Ferreira, Maciel e Paraguay, 1994, p. 224).

Há, ainda, outras alterações relacionadas a aspectos mentais não cognitivos que dizem respeito a problemas de ordem emocional ou motivacional 
e que têm sido desvelados dentro do campo da Saúde Mental do Trabalho, a partir de estudos da subjetividade dos trabalhadores, principalmente da Psicodinâmica do Trabalho4 (Dejours, 1995, 1999).

Para suportar o sofrimento, os trabalhadores estabelecem formas de defesa que não tem uma regra específica e nem leis naturais. São estratégias de condutas construídas com base no medo e na vergonha, que passam pelo retraimento da consciência diminuindo suas ações (Dejours, 1999).

Quais são as conseqüências das mudanças no trabalho para a saúde dos trabalhadores? Que tipo de patologias está sendo provocado pela desconstrução de uma habilidade desenvolvida no e para o trabalho e a reconstrução de novas, pelo aumento da intensidade do trabalho, pela diminuição salarial, pela redução dos trabalhadores no processo de trabalho, pela exacerbação do individualismo, pela desmobilização sindical, pela privatização, pela terceirização, pela flexibilização dos direitos, pela redução dos gastos sociais com a Saúde e com a Educação? Como os trabalhadores reconhecem esses agravos? Como podem preveni-los? Como melhorar a qualidade da saúde no trabalho? Como educar os trabalhadores para que reconheçam estas implicações? Que projetos de educação para a saúde podem ser construídos ou reconstruídos? Qual "educação" e para qual "saúde"?

As mudanças tecnológicas apontam para conseqüências sobre a saúde dos trabalhadores a partir da produção da insegurança que, em nível individual, traduz-se em formas diferenciadas de defesa e resistência, sejam estas nos planos moral, político, ético ou social, o que indica novas formas de produção do processo saúde-doença.

Estas determinações vão mais além de um corpo doente que resulta de um mau comportamento, da exposição a um produto tóxico presente no ambiente de trabalho, ou de um acidente decorrente de atos inseguros ou de condições físicas. E, se as determinações das doenças não se encontram mais visíveis no espaço do trabalho, estas mudanças também trazem um grande desafio para os estudiosos da educação para a saúde no trabalho. Se há novos perfis de saúde dos trabalhadores, é absolutamente necessário criar-se outras formas e outros conteúdos para as práticas educativas.

\section{Os novos desafios aos estudiosos das áreas de educação, saúde e trabalho}

Muitas críticas já foram feitas aos programas adotados para a promoção da saúde e prevenção das doenças. São programas geralmente desenvolvidos a partir de enfoques centrados no modelo hegemônico biomédico, segundo a concepção mecanicista de ser humano, em que doenças são entendidas como conseqüência do comportamento individual, do estilo de vida ou de ris- 
cos existentes no local de trabalho e no meio ambiente. De modo geral, essa visão considera o ambiente de trabalho como externo ao trabalhador, portanto ahistórico e atemporal, com o processo saúde-doença sendo determinado por uma relação direta de causa e efeito. Ao mesmo tempo, supõe que somente por meio da prevenção será possível interferir nesta relação e, assim, reduzir o vultoso investimento com os serviços de saúde e de assistência médica, uma vez que as ações curativas são extremamente dispendiosas e não estão disponíveis para a totalidade dos trabalhadores. Suas atividades pedagógicas estão fixadas em programas e campanhas fragmentados e focalizados numa luta contra as doenças, ou contra os sintomas das doenças.

A prática tem demonstrado a insuficiência dessas abordagens, levando à busca de outras explicações, a fim de que se possam levantar pontos para a discussão em torno de uma nova práxis da educação para a saúde no trabalho.

Esta nova proposta pedagógica deve partir do princípio de que são as condições de produção e reprodução que definem o processo saúde-doença, e deve tomar o trabalhador como um ser histórico, capaz de compreender e de refletir sobre a sua história, podendo (re)construí-la, desde que instrumentalizado pelo conhecimento. Uma ação educativa que vise a superação da unilateralidade e que trate da reintegração do trabalhador, tendo como horizonte o pleno desenvolvimento humano, o desenvolvimento do ser omnilateral.

\section{Propostas e diretrizes para uma nova educação para a saúde dos trabalhadores}

A partir da análise das mudanças ocorridas na refinaria estudada, identificaram-se pontos e diretrizes que podem indicar a formulação de propostas para a construção de um novo projeto de educação que, de fato, possa instrumentalizar os trabalhadores na busca por melhores condições para a saúde no trabalho, mediante a transformação da sua consciência sanitária 5 .

Muito embora se tenha claro que, para a melhoria das condições da saúde, não basta a transformação das consciências sem uma transformação das condições materiais, aquela, porém, pode ser um pressuposto desta: para que os trabalhadores possam compreender e identificar as múltiplas determinações do processo saúde-doença do trabalho, a partir e para além dos riscos, tendo como referencial o real, o concreto, ou seja, o seu trabalho e a totalidade das relações sociais na determinação das novas formas de produção da doença na atual etapa de acumulação capitalista.

Trata-se, portanto, da necessidade de rever a prática pedagógica tradicional da educação para a saúde no trabalho, indicando pontos para uma 
nova prática pedagógica que supere as atuais ações enraizadas na concepção biológica de risco ou na concepção higienista de moralização da classe trabalhadora.

Neste estudo, foram identificadas algumas dimensões desta nova pedagogia. No seu desenvolvimento, analisou-se o concreto, o homem como sujeito, o petroleiro com suas condições materiais e com sua consciência, não um petroleiro qualquer, mas um determinado petroleiro, o operador do Setor de Craqueamento de uma determinada refinaria, onde estava sendo implantado um novo instrumento de trabalho. Foi este sujeito que se observou e foi deste sujeito que se falou: de seus medos, suas tristezas, suas inquietações, suas desconfianças, suas desesperanças, mas também, de suas alegrias, seus desejos, suas expectativas, suas esperanças.

E foi a partir deste petroleiro que se concluiu que as novas tecnologias trazem, para execução do seu trabalho, modificações que provocam uma permanente insegurança, gerada pela atual dinamicidade do processo de trabalho. Esta insegurança é resultante do medo, porém, não só daquele estruturante do seu processo de trabalho, mas principalmente das modificações implantadas na refinaria na atual etapa de acumulação.

Esta mudança reside, basicamente, na destruição das condições de estabilidade e de possibilidade de conhecimento, das relações de causa e efeito sobre a saúde do trabalhador, substituindo-se o sentimento de segurança, de autocontrole, de domínio da natureza e das relações sociais e produtivas, pela insegurança traduzida pelo medo.

No taylorismo-fordismo, a segurança decorre da transparência, do domínio da imediaticidade do trabalhador na relação com o seu instrumento de trabalho, porque o trabalhador não só conhece o funcionamento da máquina por ela ter uma base eletromecânica, como domina totalmente o processo de operá-la. Assim, um acidente, por exemplo, como cortar um dedo na máquina, é tão transparente e previsível quanto a técnica com a qual ele trabalha, e, portanto, passível de prevenção. E por ser esta uma relação direta, há um nexo causal mais 'visível' entre os acidentes, os riscos, as doenças e o processo de trabalho, tornando passível de melhor controle a ocorrência de novos casos.

A introdução da automação tornou-se um avanço real, ao retirar o trabalhador das manobras consideradas insalubres do ponto de vista das exigências físicas, porém oculta a incidência dos acidentes e dos riscos que não são mais lesões físicas provocadas pela máquina ou por contaminantes do ambiente.

O desaparecimento dessa evidência física estabelece uma contradição. Ao liberar o trabalhador do comprometimento físico, ocasiona um aumento da carga psíquica que, freqüentemente, se expressa em sintomatologias de fadiga, estresse e outras alterações psicossomáticas e nervosas oriundas da 
difícil relação com o processo de trabalho. As atuais transformações do trabalho, próprias da automação industrial, muitas vezes privam o trabalhador do contato com a atividade concreta, quando este passa a executar um trabalho 'invisível' em que não toca no que faz.

Nestes casos, cabe indagar como avaliar o nexo causal dos acidentes de trabalho ou de patologias cujas tarefas envolvem uma elevada carga cognitiva e um aumento da carga emocional ou motivacional causadas pelas atuais modificações na organização do trabalho. Cabe também indagar como é possível definir, por exemplo, se o estresse é provocado pela redução do número de trabalhadores experientes no processo de trabalho, colocando em risco a segurança da unidade, ou pelo sofrimento motivado pela desregulamentação das leis trabalhistas, ou ainda pelo desconhecimento na operação da nova máquina introduzida no trabalho.

Na automação, a máquina embute a ciência, que é complexa e sofisticada, e mesmo aqueles trabalhadores que dominavam o processo anterior de trabalho agora não o dominam mais. Desta forma, o estresse aumenta, mas fica extremamente difícil estabelecer um nexo causal em virtude da mudança do caráter transparente da técnica para a 'caixa preta' da tecnologia, submetendo-se o trabalhador a um estado permanente de insegurança.

Com a nova fábrica não há mais intoxicações por produtos, não há mais risco da máquina cortar; portanto, fica mais extemporânea uma visão biologicista e reducionista sobre o processo de produção da saúde e da doença, como base para a prática da educação para a saúde. O que era risco do ponto de vista biológico, hoje, deixou de ser; o risco não se deixa identificar de imediato e vai se constituir de forma diferente, de trabalhador para trabalhador, na relação entre o corpo, o ambiente e o trabalho. O que é estresse para um trabalhador não será para outro, porque o medo se expressa de diferentes formas, muito embora também se expresse em patologias físicas.

As novas tecnologias, por um lado, libertam o trabalhador do petróleo da nocividade do ambiente físico, retirando-o da área; por outro, trazem novos problemas como a desregulamentação, a flexibilização e a redução de direitos. Ele deverá ser capaz de reconhecer esses fatos como responsáveis pelas patologias. O saber sobre riscos, sobre uso de equipamentos de proteção individual ou normas de segurança torna-se insuficiente. Para que o trabalhador possa compreender as modificações da sua saúde como conseqüência das modificações mais gerais no mundo do trabalho, é necessário que ele possua não só um conhecimento suficiente sobre o funcionamento do seu corpo, mas também sobre os produtos e processos que estão envolvidos no desenvolvimento do seu processo de trabalho e sobre como estes se articulam com as novas relações sociais e produtivas típicas do atual processo de acumulação.

Portanto, a questão da educação para a saúde deve se colocar sob um novo ponto de vista e a partir de um novo paradigma. Isto significa que a 
primeira etapa da educação para a saúde começa com uma boa educação básica, com um conhecimento científico tecnológico de qualidade. O trabalhador necessita dominar os conhecimentos científicos e sócio-históricos que envolvem e explicam todo seu trabalho para além do seu corpo.

Tal educação deve levar o trabalhador à compreensão de que a acumulação flexível traz outros problemas que ele vai ter de reconhecer, como um novo conceito de trabalho em que ele perde a proteção do Estado e a empresa tende a não se responsabilizar mais pelas doenças do trabalho. $\mathrm{O}$ não estabelecimento do nexo causal pode se tornar, assim, uma exploração muito mais violenta, uma submissão do ser humano e de seus ideais a um emprego que lhe permite apenas comer, como um retorno à barbárie.

No dizer de Kurz,

"os indivíduos flexibilizados pelo capitalismo não são pessoas conscientes e universais, mas pessoas universalmente exploradas e solitárias. A nova responsabilidade pelo risco não é algo instigante se não aterrador, pois o que se arrisca é a própria vida. A desconfiança generalizada corre mundo. Do clima de máfia e paranóia nasce uma cultura empresarial taciturna. Pessoas sem assistência e espoliadas ficam doentes e perdem a motivação. E tornam-se cada vez mais superficiais, dispersas e incompetentes" (Kurz, 1999, p. 5-7).

A acumulação flexível que trouxe a automação e os processos computadorizados apresenta novos problemas e novas necessidades, uma vez que as novas tecnologias demandam outras formas de relação entre educação e trabalho, agora mediadas não mais pelas formas de fazer, mas por competências cognitivas superiores.

É necessário que se delineiem novas premissas para um novo projeto pedagógico na área de educação para a saúde, incluindo também uma nova formação para os profissionais da área, com sensibilidade ética e intuição histórica, a fim de que sejam capazes de compreender as novas determinações do processo saúde-doença a partir das modificações no mundo do trabalho.

Portanto, educar para a saúde tem um significado muito maior do que informar sobre saúde. Significa possibilitar o acesso à ciência contemporânea, ou seja, ao saber sistematizado, elaborado, socialmente produzido. É possibilitar aos homens a apropriação do saber científico buscando "a superação do senso comum e a sua elevação ao conhecimento filosófico" (Gramsci, 1991, p. 11).

O conhecimento a ser desmonopolizado deve ser um conhecimento no sentido da integração do trabalhador em sua totalidade, como ser humano omnilateral, que transforma e humaniza a natureza para assim se transformar, se humanizar. Isto é, de um indivíduo que está exposto às múltiplas determinações das doenças, relativas a momentos específicos em cada modo 
de produção. Por isso, deve-se superar o conhecimento do ser humano como se ele fora apenas fragmento, um corpo exposto ao processo de produção, uma máquina humana. É necessário compreender que as doenças do trabalho são a expressão concreta da relação entre capital e trabalho, ou seja, refletem as particularidades da organização do trabalho, das modificações no processo de trabalho, da exigência da produtividade, das políticas de desenvolvimento econômico, da impossibilidade de organização dos trabalhadores em defesa de seus interesses.

E com base nessa compreensão, é fundamental que se proponham pontos para a discussão em defesa da saúde e segurança dos trabalhadores, a partir de uma profunda revisão da prática pedagógica da educação para a saúde que supere as atuais limitações de forma e de conteúdos, em direção a uma nova proposta fundada em pressupostos como:

- tomar como princípio a saúde dos trabalhadores como um processo integral, tendo, como elemento fundante da sua produção, o trabalho na sua totalidade, ou seja, em toda sua dimensão social, econômica e política;

- compreender a área da educação para a saúde, dada a sua complexidade, como um campo transdisciplinar do conhecimento em que as ciências interagem de forma singular na construção do objeto;

- integrar a educação para a saúde à educação básica, viabilizando o acesso aos fundamentos científicos que subsidiem a compreensão de que são as diversas formas de inserção do ser humano no processo produtivo que determinam os diferentes perfis de viver, de adoecer e de morrer;

- incluir na educação para a saúde dos trabalhadores a compreensão dos princípios da Reforma Sanitária brasileira, quais sejam o da universalidade, igualdade e integralidade de ações previstas no Sistema Único de Saúde, que pressupõem assistência à saúde do trabalhador de qualidade, a fim de instrumentalizá-lo para a luta política na manutenção e ampliação das conquistas (Brasil, 1989, arts.196 e 198/88);

- incluir, nos cursos de formação dos profissionais da área da saúde, a articulação entre o conhecimento do trabalho, da sua forma de gestão e organização e de seus determinantes sobre o processo saúde-doença, nos diferentes períodos de acumulação do capital;

- $\quad$ promover a reflexão sobre o futuro da educação dos trabalhadores, considerando as atuais mudanças sociais, econômicas e políticas com a adoção da política neoliberal que se expressa na flexibilização e desregulamentação do trabalho, na privatização das empresas e de serviços públicos, que repercutem na saúde e na qualidade de vida da população em geral e em particular dos trabalhadores;

- $\quad$ promover uma prática pedagógica de educação para a saúde no trabalho com a participação ativa dos trabalhadores, possibilitando a formação de mais um espaço de participação política na sua organização; 
- viabilizar a apropriação dos conteúdos da legislação não só para o reconhecimento dos seus direitos a fim de que os trabalhadores exijam seu cumprimento, mas principalmente para que possam fazer a crítica às suas limitações quanto às novas determinações na geração das doenças.

De resto, é imprescindível construir um novo conhecimento sobre educação para a saúde no trabalho, para 'desmonopolizá-lo', entendendo desmonopolização como a apropriação pelos trabalhadores do que lhes é de direito: o conhecimento e o domínio sobre seu próprio corpo, sobre sua própria saúde e, fundamentalmente, sobre as múltiplas determinações do processo saúde-doença, frente às atuais mudanças da acumulação flexível.

Nesta perspectiva, portanto, educar não significa educar só para a saúde, significa educar para uma formação integral dos sujeitos como atores sociais críticos que compreendam e que questionem as relações sociais.

\section{Notas}

1 Professora do Departamento de Saúde Comunitária do Setor de Ciências da Saúde da UFPR. Especialista em Odontologia Social e Preventiva pela UFRGS e mestre em Educação pela UFPR. < bethgarzuze@uol.com.br>

2 Os conceitos de mais-valia absoluta e relativa são de Marx, que os desenvolveu em várias partes de $O$ Capital, e das quais extraímos a seguinte definição: “O prolongamento da jornada de trabalho produz a mais-valia absoluta (...). Ela constitui o fundamento do sistema capitalista e o ponto de partida da produção da mais-valia relativa (...). A produção da mais-valia relativa revoluciona totalmente os processos técnicos de trabalho e as combinações sociais (...) Só é possível elevar a taxa da mais valia variando relativamente as magnitudes das suas partes componentes, o trabalho necessário e o trabalho excedente, o que pressupõem (admitida a hipótese de que o salários não deve cair abaixo do valor da força de trabalho) variação da produtividade ou da intensidade do trabalho. Do ponto de vista social, a produtividade aumenta sua economia. Esta implica em economizar meios de produção e em evitar trabalho inútil (Marx, 1994, p. 585-607).

3 Utilizamos a expressão no singular — "Sistema Descentralizado de Controle Digital" - para nos referirmos ao instrumental implantado em uma refinaria específica e no plural - "Sistemas Descentralizados de Controle Digital" — para nos reportarmos genericamente à tecnologia.

4 A definição é de Dejours: 'Esta disciplina, que tem implicações nos campos psicológico e sociológico, portanto na contracorrente do behaviorismo, tem por objetivo o estudo clínico e teórico da patologia mental decorrente do trabalho, onde a questão do sofrimento psíquico ocupa uma posição central' (Dejours, 1995, p. 25).

5 Adaptei de Giovanni Berlinguer (1983) a definição de consciência sanitária como sendo a tomada de consciência de que a saúde é um direito e não um valor. 


\section{Referências}

ARAÚJO, Elizabeth G. S. 1999. A educação para a saúde dos trabalhadores no contexto da acumulação flexível. Dissertação de Mestrado, Paraná: Setor de Educação. Curso de Educação. Universidade Federal do Paraná.

BERLINGÜER, Giovanni. 1983. A saúde nas fábricas. São Paulo: Cebes-Hucitec.

BRAGA, Ruy. 1997. A restauração do capital. São Paulo: Xamã.

BRASIL. 1989. Constituição da República Federativa do Brasil. São Paulo: Atlas.

BRAVERMAN, Harry. 1987. Trabalho e capital monopolista: a degradação do trabalho no século XX. 3. ed. Rio de Janeiro: Guanabara.

CASTRO, Nádia. A.; GUIMARÃES, Antonio. S. 1991. Competitividade, tecnologia e gestão do trabalho: a petroquímica brasileira nos anos 90. In: LEITE, Márcia de P; SILVA, Roque A. da (orgs.) Modernização tecnológica: relações de trabalho e práticas de resistência. São Paulo: Iglu, p. 41-65.

DEJOURS, Christophe. 1995. A loucura do trabalho. 5. ed. ampliada. São Paulo: Cortez. 1999. A banalização da injustiça social. Rio de Janeiro: Fundação Getúlio Vargas.

DUARTE, Francisco José de C. M. 1994. A análise ergonômica do trabalho e a determinação de efetivos: estudo da modernização tecnológica de uma refinaria de petróleo do Brasil. Tese de Doutorado, Rio de Janeiro: COOPE - Universidade Federal do Rio de Janeiro.

1995. A modernização tecnológica da REPAR: uma abordagem ergonômica. Relatório de pesquisa. Refinaria Getulio Vargas. Araucária. (Versão provisória). Mimeo.

FERNANDES, Luis. 1995. Neoliberalismo e reestruturação capitalista. In: SADER, Emir \& GENTILLI, Pablo.(orgs.) Pós-neoliberalismo: as políticas sociais e o Estado democrático. São Paulo: Paz e Terra, p. 54-61.

FERREIRA, Leda L.; MACIEL, Regina; PARAGUAY, Ana I. 1994. A contribuição da ergonomia. In: BUSCHINELLI, J. T. (org.) Isto é trabalho de gente? Vida, do- ença e trabalho no Brasil. Petrópolis, RJ: Vozes, p. 215-231.

GRAMSCI, Antonio 1991. Concepção dialética da história. 9. ed. Rio de Janeiro: Civilização Brasileira.

HARVEY, David. 1996. Condição pós-moderna. 6. ed. São Paulo: Loyola.

KUENZER, Acácia Z. 1989. A pedagogia da fábrica. 3. ed. São Paulo: Cortez.

1996. Globalização e universidade: os impactos das mudanças tecnológicas sobre a educação do trabalhador. In: Seminário Globalização e Estado: universidade em mudança. Curitiba, UFPR e SENAI, p. 29-52.

KURZ, Robert 1999. Descartável e degradado. Folha de S. Paulo, 11 jul. Mais, pp. 5-7.

MARX, Karl. 1983. Contribuição à crítica da economia política. São Paulo: Martins Fontes. 1994. O capital: crítica da economia política. Livro 1. O Processo de produção do capital. v. I e II. 14.ed. Rio de Janeiro: Bertrand do Brasil.

MARX, K. \& ENGELS, F. s.d. A ideologia alemã. v. I. 4. ed. Portugal/Brasil: Editorial Presença/Martins Fontes. (Coleção Síntese).

PETROBRAS. 1989. PDAI/89. Plano Diretor de Implantação da Automação Industrial da Petrobras. Rio de Janeiro. (Mimeo.)

REVISTA DA PETROBRAS. 1996. Ano II, n. 25.

SALGADO, Antonio A. \& PERTENCE NETO, Argemiro. 1993. Petróleo. In: TAVARES, Maria C. et. al. O Estado que nós queremos. Rio de Janeiro: Espaço E Tempo (Coleção Brasil Hoje), p. 9-37.

SINGER, Paul. 1996. Globalização, Estado e Universidade. In: Seminário Globalização e Estado: universidade em mudança. Curitiba, UFPR e SENAI, p. 1-27.

TEIXEIRA, Francisco J. S. (org.) 1998. Neoliberalismo e reestruturação produtiva: as novas determinações do mundo do trabalho. 2. ed. São Paulo: Cortez.

Recebido em 30/07/2003

Aprovado em 13/07/2004 